\title{
Como a escola pode ser mais justa e mais eficaz? ${ }^{1}$
}

Marcel Crahay

Professor titular da Resumo: Recorrendo a um amplo levantamento de pesquisas Universidade de Genebra

E-mail:mcrahay@mac.com e estudos de grandes pensadores do campo da educação, Marcel Crahay discorre neste artigo sobre a relação entre opções éticas e os dispositivos e práticas educacionais que estruturam o processo de ensino e aprendizagem. 0 autor trata dos tipos de dispositivos e práticas educacionais que têm gerado melhores resultados em termos de uma distribuição mais justa do conhecimento. Analisa ainda a relação entre tais práticas e princípios éticos e de justiça. Conclui que a igualdade de conhecimentos adquiridos, cuja base é o princípio de justiça corretiva, é a ideologia pedagógica mais adequada à educação básica porque contempla vários requisitos que as pesquisas indicam necessárias à aprendizagem de todos, tais como o respeito aos distintos ritmos de aprendizagem e a necessidade de adequação e mudanças contínuas do processo de ensino, com base em avaliação formativa. Além disso, essa ideologia pedagógica considera as provas científicas de inexistência de dons naturais, colocando-se contrária aos dispositivos e práticas educacionais que oferecem oportunidades de ensino desiguais devido ao princípio meritocrático².

Palavras-chave: Práticas educativas. Desigualdade escolar. Equidade. Ensino. Educação básica.

Tradução: Fernando Santos; revisão técnica: Vanda Mendes Ribeiro.

Resumo e palavras-chave elaborados por Vanda Mendes Ribeiro. 
QUE FUNÇÃO(ÕES) SOCIAL(IS) A ESCOLA DEVE CUMPRIR?

Desde a metade do século $X X$, inúmeras expectativas foram postas na universalização da escolarização. Além do avanço democrático que esse fenômeno representa, dois outros efeitos importantes foram conscientemente buscados por aqueles que batalharam pela universalização da escolaridade.

Indivíduos que, ao longo da primeira infância, são educados de um modo comum, apresentam um nível de identidade, no modo de ser e nos valores que expressam, superior àqueles cuja educação é deixada ao acaso. Em outras palavras, a escola pode ser um elemento de coesão social. Jules Ferry, que foi, na França, o pai da escola republicana, compreendeu claramente que, ao favorecer uma uniformização de conhecimentos e de valores, a escola podia contribuir para a construção da nação francesa ${ }^{3}$. Doravante, a escola também tende a se tornar um agente importante de unificação da sociedade europeia, e até mesmo de uma sociedade global ${ }^{4}$.

A universalização da escola adquire igualmente muito sentido quando se consideram as teorias do capital humano (BECKER, 1993). Neste início de século XXI, quando a preocupação com o desempenho e a produtividade é constante, parece oportuno investir na inteligência. Portanto, a escola representa um investimento a prazo que a sociedade faz na expectativa de obter dividendos substanciais em termos de competências e, até mesmo, de capacidades específicas.

Não podemos conceber a finalidade da escola num vazio sociológico. A sociedade - ou, mais precisamente, seus grupos dominantes - exige que a escola produza um tipo de indivíduo adaptado a suas estruturas e a seus modos de funcionamento. Ao assumir essa tarefa, a escola participa da socialização das crianças ${ }^{5}$. Com efeito, ela lhes transmite crenças, valores, normas, saberes e savoir-faire próprios da sociedade na qual se insere.

3 Antes de Jules Ferry e de todos os fundadores da escola moderna, a Igreja já havia percebido a influência positiva que o ensino poderia desempenhar sobre a maneira de viver e de pensar dos indivíduos. Todavia, essa instituição não se esforçou - por falta de recursos e de vontade - para estender os benefícios da educação a todos os indivíduos. Por outro lado, é preciso considerar que, ao favorecer a unificação dos saberes e dos valores, a escola torna-se um instrumento político de padronização, com vantagens (em especial, o fortalecimento da coesão social) e inconvenientes (sobretudo no que tange à eliminação das particularidades culturais locais e à diminuição dos laços de solidariedade comunitária).

4 É preciso acrescentar: com o risco de se tornar um instrumento ideológico que veicula uma visão tecnocrática da sociedade.

5 Alguns sociólogos franceses chegam a adotar o termo aculturação, de origem inglesa, que expressa claramente a ideia de que o indivíduo se insere numa cultura apropriandose dela. 
O professor é um agente dessa sociedade. Seu papel é fazer com que a maioria de seus membros adquira os conhecimentos e competências que a sociedade espera que eles sejam capazes de dominar. Ele também tem a missão de fazer com que os valores e a cultura - que constituem a base dessa sociedade - sejam compartilhados por todos. Quanto ao aluno, espera-se que ele aprenda papéis, saberes e competências e que interiorize normas e valores que permitirão que ele se integre na sociedade e assuma funções úteis para o seu desenvolvimento.

Ao lado dessa função de socialização, a escola assume uma função de educação. Essa ideia é uma herança da filosofia lluminista. Embora seja verdade que a escola tem deveres com relação à sociedade, ela também os tem com relação aos indivíduos. No livro Courants et contre-courants de la pédagogie contemporaine [Correntes e contracorrentes da pedagogia contemporânea], Hameline (1986, p. 15) explica que "A educação escolar tal como a conhecemos hoje é uma expressão da modernidade". Ora, como demonstrou Touraine em Critique de la modernité [Crítica da modernidade] (1992), esta educação moderna se constituiu em ideologia. Ela proclama o "triunfo da razão", a perfectibilidade do ser humano e a possibilidade de que ele torne um indivíduo autônomo, desde que utilize sua capacidade de pensar. 0 homem não nasce livre, ele se emancipa por meio do exercício da razão. Quanto ao bom funcionamento da democracia, pressupõese necessariamente que a sociedade seja composta de seres racionais. Portanto, a escola contemporânea é filha de Condorcet. Ela é conduzida pelo desejo de estender a todos os homens o que era prerrogativa de alguns comportar-se de acordo com a razão. A educação dos cidadãos não pode, portanto, conduzir à doutrinação. Não se trata de convencê-los de uma verdade qualquer preestabelecida. A partir desse momento, vemos emergir o motivo ideológico essencial da escola moderna: é preciso fazer do indivíduo um homem libertando-o de crenças, superstições ou ideias preconcebidas. A finalidade da escola nada mais é que a emancipação do homem por meio do desenvolvimento da razão.

A escola pode, ademais, contribuir para a distribuição de papéis e de posições na sociedade. Com efeito, ao fazer com que sejam adquiridas qualificações escolares que apresentam uma determinada utilidade social, a escola participa na distribuição de empregos, de posições e de status sociais ${ }^{6}$. Ao certificar os níveis de qualificação, ela não apenas assume uma função importante na distribuição das profissões, como também determina o lugar

6 Dubet e Martucelli (1996). 
que os indivíduos irão ocupar na hierarquia social. Queira ou não, a escola não escapa dessa finalidade (de utilidade) social; mais do que nunca, essa finalidade está imposta à escola7. Ela assegura uma função de especialização e de distribuição das posições sociais.

A pergunta geral que devemos responder hoje diz respeito ao modo como a instituição escolar deve cumprir essas três funções: de socialização, de educação e de especialização e distribuição das posições sociais (função de utilidade).

JUSTIÇA IGUALITÁRIA, MERITOCRÁTICA OU CORRETIVA?

As instituições sociais supõem regras éticas. Numa sociedade moderna, a justiça deve imperar em todas as áreas: polícia, exército, tribunais e mundo político, mas também na escola. Portanto, a escola deve ser justa. Ninguém contesta essa afirmação. Resta definir o que se entende por justo.

De maneira um pouco sumária, podemos fazer com que o debate ético em matéria de justiça discuta três princípios básicos (CRAHAY, 2013). Por um lado, podemos declarar a igualdade fundamental de todos os seres humanos - um homem vale tanto quanto outro - e, consequentemente, exigir que cada um deles tenha o mesmo direito à proteção civil, à saúde, à educação... Portanto, em virtude do princípio de justiça igualitária, exigiremos que todos os cidadãos tenham a mesma segurança, que todos os pacientes tenham a mesma qualidade de atendimento em saúde e que todas as crianças tenham a mesma qualidade de ensino. Por outro lado, podemos argumentar que convém que, na sociedade, cada um seja recompensado ou valorizado de acordo com seus méritos próprios. Nesse caso, estaremos falando de justiça meritocrática. Nessa perspectiva, parece legítimo atribuir um salário mais alto aos indivíduos mais competentes e/ou que trabalhem mais. Na escola, consideraremos justo atribuir notas mais altas aos alunos que alcançarem um melhor desempenho. Resumindo, a regra a ser respeitada seria: "a cada um segundo seu mérito ou segundo seu talento". Por fim, podemos observar que essa concepção burguesa de justiça apenas ratifica as desigualdades naturais existentes entre os indivíduos e argumentar em defesa de uma justiça corretiva: a sociedade deveria agir no sentido contrário das vantagens das quais alguns podem se orgulhar. Nessa perspectiva, então, acharemos justo que o Estado socorra os mais desfavorecidos e, de maneira mais

Essa discussão merece ser matizada. Alguns - em especial Y. Illich - sonham com ou propõem uma escola que assuma, sobretudo, as funções de socialização e de educação, e pouco - ou nada - a função de distribuição de papéis. 
geral, se esforce para promover a máxima igualdade para todos, recorrendo eventualmente a procedimentos corretivos voltados para os mais fracos. Quanto à escola, caberia a ela lutar contra o peso das desigualdades de origem social, levando todos os indivíduos a adquirir os aprendizados fundamentais. Essa concepção pedagógica nos leva a considerar justo que se dê mais atenção àqueles que enfrentam as dificuldades mais significativas.

Esse debate ético levou a três concepções de igualdade na pedagogia: igualdade de tratamento, igualdade de oportunidades e igualdade de resultados, ou melhor, de aquisição ${ }^{8}$.

\section{IGUALDADE DE TRATAMENTO E IGUALDADE DE OPORTUNIDADES}

Os fundamentos éticos do nosso sistema educativo encontram-se no famoso texto de Condorcet, Rapport et projet de décret sur l'organisation générale de l'instruction publique [Relatório e proposta de decreto sobre a organização geral do ensino público] (1972 apud CRAHAY, 2013). O filósofo francês escreve:

\footnotetext{
[...] nossa primeira preocupação deveria ser, de um lado, tornar a educação igualitária e universal, e, de outro, tão completa quanto as circunstâncias o permitissem; seria preciso oferecer a todos, igualmente, a educação que é possivel estender a todos; e não recusar a nenhuma parcela dos cidadãos a educação mais elevada impossivel de compartilhar com o conjunto de todos os cidadãos.
}

A proposta é clara: trata-se de assegurar a igualdade de tratamento no nível da educação básica e a igualdade de oportunidades, em seguida. A justiça igualitária, que exige que cada um receba o mesmo que o outro, é satisfeita no primeiro nível da escolaridade; oferecemos a todos, indistintamente, a mesma educação. Quanto à justiça distributiva, que exige que cada um receba o que lhe é devido de maneira proporcional a suas potencialidades, ela se realiza no nível superior do currículo escolar.

O Terror, o Império bonapartista, a Restauração e todos os acontecimentos

A igualdade de tratamento corresponde ao ideal de justiça igualitária; a igualdade de oportunidades ao da justiça distributiva (meritocrática) e a igualdade de aquisição ao da justiça corretiva. Assim, a igualdade de tratamento é respeitada quando todos os alunos recebem a mesma qualidade e os mesmos conteúdos de ensino. A igualdade de oportunidades será satisfeita se as oportunidades educacionais mais ricas forem oferecidas àqueles que são realmente os mais merecedores, o que pressupõe uma identificação objetiva dos talentos e dos méritos. Por fim, os que sonham com a igualdade de aquisição consideram que é legítimo dar mais aos mais desfavorecidos no plano intelectual e cultural, a fim de criar uma nova situação na qual todos os indivíduos sejam dotados de competências consideradas fundamentais para se desenvolver na sociedade do século XIX. 
que sacudiram a Europa durante os dois primeiros terços do século XIX, impediram que esse espírito fecundasse as instituições educacionais. Essa perspectiva renasce no final do século XIX com Jules Ferry e, sobretudo, com os pioneiros da Nova Educação: E. Claparède, O. Decroly, C. Freinet, P. Langevin, $\mathrm{H}$. Wallon, etc.

O esquema de Condorcet servirá de inspiração para todas as reformas escolares do fim do século XIX e do começo do século XX. Em torno dele irá se formar uma unanimidade quase absoluta. Porém, as críticas irão se acumular a partir do final dos anos 1960.

A ideologia da igualdade de oportunidades postula que há em cada um nós aptidões naturais mais ou menos nobres. É esse axioma que sustenta tudo: se é verdade que as crianças têm aptidões diferentes que as tornam mais ou menos capazes de aspirar, de maneira realista, a uma formação de acordo com suas capacidades, cabe ao Estado ou à escola identificar o potencial de formação próprio a cada um, atualizá-lo da melhor maneira possível, isto é, dar a cada um a oportunidade para que alcance seu mais amplo progresso. Essa definição da missão educacional da escola é acrescida de uma responsabilidade complementar: eliminar os obstáculos geográficos, financeiros, institucionais, culturais e psicológicos que poderiam impedir que o indivíduo tivesse acesso ao nível de formação que é capaz de adquirir por ele próprio. Convém, portanto, afastar do caminho que conduz cada indivíduo ao seu pleno desenvolvimento os obstáculos relacionados à origem social.

Reencontramos esse conceito no projeto Longevin-Wallon, onde se lê o seguinte:

Todas as crianças, qualquer que seja sua origem familiar, social e étnica, têm o mesmo direito ao desenvolvimento máximo que sua personalidade comporte. Elas não devem encontrar nenhuma outra limitação que não seja a de suas aptidões. Portanto, o ensino deve oferecer a todos possibilidades iguais de desenvolvimento, oferecer a todos o acesso à cultura, democratizar-se menos por uma seleção que distancie os mais dotados do povo do que por uma elevação contínua do nível cultural do conjunto da nação. A introdução da 'justiça na escola' por meio da democratização do ensino porá cada um no lugar que suas aptidões lhe permitam, para o bem superior de todos. ${ }^{9}$

Graças aos trabalhos de Piaget (1970) e, sobretudo, aos trabalhos de Bloom (1953; 1964; 1968; 1972a; 1972b; 1973; 1974a; 1974b; 1976; 1979; 1986) e de seus colaboradores, a noção de aptidões naturais é hoje amplamente questionada. Em todo caso, nada permite que façamos dela uma espécie de diamante encerrado nas profundezas do ser humano. Certamente, a loteria genética dota os bebês de características que lhes são próprias, inclusive no

9 Projeto Langevin-Wallon, citado por Derouet (1992), p. 148. 
plano das aptidões intelectuais. No entanto, conforme os trabalhos de Bloom mostraram, o potencial de aprendizagem básica da imensa maioria de crianças é suficientemente amplo para permitir que se esperem níveis de competência absolutamente sólidos (e mesmo brilhantes) nas diversas áreas que nossos sistemas escolares se esforçam para que elas dominem. Atribuir os fracassos ou as dificuldades que muitos alunos encontram à ausência de dons inatos é ignorar os inúmeros obstáculos que o ambiente familiar ou escolar, em geral pouco propícios, podem impor em seus caminhos. É desprezar o peso da herança social e, mais ainda, do efeito das interações que a criança mantém com o ambiente familiar e escolar. 0 que a criança é aos 5 ou 6 anos de idade resulta das múltiplas interações que ela teve com o seu meio. 0 geneticista Jacquart explica claramente, em várias de suas obras, que é ridículo querer separar, na mente de um indivíduo, o que é inato daquilo que foi adquirido. $E$, mais importante! A psicologia e, em particular, a psicologia cognitiva, mostrou que a velocidade de aprendizagem e, de maneira correlata, as estratégias de aprendizagem, podem ser modificadas. Portanto, podemos ajudar os mais lentos a aprender com maior rapidez e conduzir, de maneira adequada, o aluno que comete um erro.

Finalmente, a partir de 1966, em L'école conservatrice [A escola conservadora], Pierre Bourdieu (1966) denunciou a perversidade dissimulada debaixo do princípio de igualdade de tratamento. Segundo ele

para que sejam favorecidos os mais favorecidos e desfavorecidos os mais desfavorecidos, é preciso - e basta - que a escola ignore no conteúdo do ensino transmitido, nos métodos e nas técnicas de transmissão e nos critérios de julgamento as desigualdades culturais existentes entre as crianças de diferentes classes sociais. Em outras palavras, ao tratar todos os aprendizes, por mais desiguais que sejam, como iguais em direitos e deveres, $o$ sistema escolar é levado a sancionar, de fato, as desigualdades iniciais diante da cultura (BOURDIEU, 1966, p. 336-337). ${ }^{10}$

Dessa forma, o esquema de Condorcet foi posto abaixo: a igualdade de tratamento na escola fundamental não consegue assegurar a justiça igualitária. No nível superior do currículo, a igualdade de oportunidades apenas confirma as desigualdades de origem social.

Em suma, a menos que se suponha que todos os homens nascem iguais e

${ }_{10}$ A nosso ver, essa citação apresenta, fundamentalmente, um interesse histórico: a ideia que ela veicula subverteu o pensamento pedagógico. Com o recuo que três décadas possibilitam, seria necessário proceder a uma análise crítica da tese de Bourdieu. Os dados das pesquisas de que dispomos hoje tentam mostrar que a igualdade de tratamento nunca aconteceu no interior dos sistemas escolares. É preciso reconhecer que a desigualdade social do êxito escolar é fruto, em grande parte, de uma sequência de discriminações negativas, isto é, de abordagens pedagógicas que favorecem os alunos melhores e prejudicam os mais fracos. 
se beneficiam de um ambiente familiar que oferece estímulos equivalentes quanto à qualidade e quantidade, a igualdade de tratamento é uma ilusão. Como não se pode considerar que esta última hipótese seja verdadeira, convém deixar para trás a ilusão da igualdade de tratamento concebendo um modelo educacional compatível com o princípio da justiça corretiva.

\section{DISCRIMINAÇÕES POSITIVAS E IGUALDADE DE CONHECIMENTOS ADQUIRIDOS ${ }^{11}$}

Abalada pelo desenvolvimento das ciências humanas, a escola está em busca de um novo contrato ético. No que diz respeito à escola fundamental, parece que começa a se esboçar um novo consenso, articulado em torno dos conceitos de discriminação positiva e de igualdade de conhecimentos adquiridos no que diz respeito às competências fundamentais.

O princípio das estratégias que visam à igualdade das aquisições é simples: 0 ensino deve ser organizado em função dos objetivos a serem alcançados por todos. Considera-se que se alcançou o domínio do assunto se os critérios que definem a competência desejada forem satisfeitos. Quanto aos meios, eles devem variar segundo as necessidades do indivíduo. É nessa perspectiva que o conceito de diferenciação pedagógica assume todo o sentido. Contudo, não se trata de cair numa outra mistificação. Diferenciar o ensino pode ter dois sentidos diferentes. No primeiro, compatível com a ideologia da igualdade de oportunidades, considerar-se-á que é necessário tornar real uma escola sob medida $^{12}$, isto é, uma escola que ofereça oportunidades educacionais que sejam proporcionais aos talentos de cada um. No segundo sentido, consoante aos princípios da justiça corretiva, convém levar em conta a diversidade individual para conduzir cada aluno ao domínio dos objetivos definidos como fundamentais.

Portanto, o fundamento dos debates relativos à escola de sucesso não é de natureza técnica. Ele é, antes de tudo, ético ou - se ainda ousamos empregar

11 Nota da revisão técnica: o termo égalité des acquis foi traduzido pela editora Piaget em 2002 por igualdade de conhecimentos. Vanda Mendes Ribeiro (2012) traduziu o conceito para igualdade de conhecimentos adquiridos. Neste artigo, manteremos a tradução feita por Ribeiro. Para conhecer a tradução portuguesa: CRAHAY, Marcel. Poderá a escola ser justa e eficaz?: da igualdade das oportunidades à igualdade dos conhecimentos. Trad. Vasco Farinha. Lisboa: Instituto Piaget, 2002. (Horizontes Pedagógicos, 92). [Original 2000]. Para conhecer a tese de Ribeiro: RIBEIRO, Vanda Mendes. Justiça na escola e regulação institucional em redes de ensino do estado de São Paulo. 455 f. Tese (Doutorado em Educação) - Faculdade de Educação da Universidade de São Paulo. São Paulo, 2012.

12 Tomamos emprestado de propósito o título de uma obra de E. Claparède (1920) que exprime, com grande clareza, esse ideal pedagógico que não podemos deixar de qualificar de elitista. 
este termo - ideológico. Enquanto cobrávamos da escola do passado que ela oferecesse o mesmo tempo de aprendizagem a todos os alunos e que os tratasse da forma mais igualitária possível, agora exigimos que ela garanta a todos um viático de competências fundamentais.

Mais do que nunca, o conceito de tratamento das diferenças merece a atenção dos professores. Trata-se, para eles, de evitar, o quanto puderem, as discriminações negativas para promover as discriminações positivas. Por discriminação negativa devem-se entender todas as formas de gestão das diferenças que levem a sua ampliação. Inversamente, as discriminações positivas tendem a reduzir as desigualdades. As possibilidades de trajetórias que especializam muito cedo no âmbito da educação básica, as classes divididas por nível e os programas avançados para as crianças superdotadas referem-se à primeira categoria; as zonas de educação prioritária, os programas compensatórios, as escolas de reforço destinadas às crianças das classes populares e a avaliação formativa referem-se à segunda. Poderíamos acrescentar a essa segunda categoria: as práticas de tutelagem, a aprendizagem cooperativa e todos os mecanismos de apoio que têm como objetivo ajudar aqueles que enfrentam qualquer dificuldade duradoura ou momentânea.

\section{ALgUNS RESULTADOS DAS PESQUISAS}

Todos os alunos são capazes de aprender, mas em ritmos diferentes

Ainda hoje, muitos professores e muitos pais pensam que alguns indivíduos são dotados para o estudo e outros não. A convicção está enraizada em crenças tradicionais que, no início do século XX, assumiram a forma de teorias científicas.

Para autores como os franceses Binet e Wallon, o suíço Claparède e, em menor medida, o belga Decroly, os seres humanos nascem dotados de diversas aptidões que determinam seu futuro. Alguns são dotados de uma atitude prática, e, portanto, feitos para as atividades manuais. Outros estão destinados a se tornar artistas, porque dispõem, desde o nascimento, da aptidão correspondente. Outros, ainda, são dotados de aptidões intelectuais e têm todas as condições de ser bem-sucedidos nos mais elevados níveis de estudos. Em suma, esses primeiros psicólogos consideravam possível medir, com a ajuda de testes de inteligência, de aptidão ou de rendimento adequados, as características individuais, consideradas como traços quase permanentes da pessoa. 
Essascrenças em matéria de psicologia desembocaram nasteoriaspedagógicas que influenciaram profundamente o ensino e a organização dos sistemas escolares no início do século XX. Assim, em L'école sur mesure [A escola sob medida], publicado em 1920, Claparède desenvolve uma argumentação com três pontos. Inicialmente, ele se dedica a demonstrar a existência de aptidões variadas nos indivíduos. Em seguida, defende a necessidade pedagógica de se levar isso em conta. Por fim, recomenda uma série de reformas baseadas nessa teoria das aptidões. Não nos demoraremos no primeiro argumento desenvolvido pelo psicopedagogo suíço nem na tipologia de aptidões que ele propõe. Doravante, essas ideias devem fazer parte do museu da história da pedagogia. Mais interessante para o nosso propósito é o modo como ele desenvolve a necessidade pedagógica de se levar em conta a diversidade de aptidões. Sustentando que é imperativo "obedecer à natureza da criança caso se queira extrair algo dela”, ele afirma que "a observação mostra que, no planeta em que nos encontramos, o indivíduo só rende na medida em que recorremos a suas capacidades naturais, e que é perda de tempo querer teimar em extrair dele capacidades que ele não tem”. Claparède esforça-se para provar a justeza de sua ideia por meio de uma analogia. Ele escreve: "Não seria desperdício de tempo querer extrair a todo custo carvão de um terreno que só contém ferro, ou cultivar trigo num solo que só é apropriado para a vinha?" (p. 60).

Foi de acordo com essa teoria, que afirma o caráter inato e imutável das aptidões, que se construiu a maioria dos sistemas de ensino, inclusive o ensino renovado. 0 princípio geral que guiou a concepção da escola poderia ser anunciado assim: já que é necessário respeitar as diferenças naturais, convém dar a cada indivíduo o lugar que the cabe na sociedade. A escola tem um papel a desempenhar nessa visão tão ordenada do mundo; cabe a ela propor modelos de educação feitos sob medida. Aquele cuja aptidão prática destina ao ofício manual será orientado para as especializações técnicas ou profissionais. Aqueles que são feitos para as ideias complexas e abstratas serão direcionados para o ensino geral. Dentre esses, podemos estabelecer ainda algumas divisões. Assim, aqueles que têm o dom da matemática escolherão a orientação "forte em matemática”. Os que possuem dons literários optarão por uma orientação composta por um grande número de horas de francês. Os que têm o dom para línguas terão um grande número de horas de línguas estrangeiras. 
Essa doutrina pedagógica começou a ser posta abaixo no início dos anos 1960. Foi nesse momento que os trabalhos do suíço Piaget (1970) começaram a ser amplamente popularizados. Para esse psicólogo, que estudou o desenvolvimento da criança durante mais de 50 anos, a inteligência é construída. O jovem bebêvem ao mundo com algumas ferramentas intelectuais rudimentares. Ao se esforçar para se adaptar ao mundo e para compreendêlo, ele irá enriquecer o conjunto de suas competências e conhecimentos; a criança deve reconstruir as conquistas intelectuais da humanidade que ocorreram lentamente. Com a ajuda dos pais, dos professores e dos colegas, ele vai reinventar o conceito de número, a noção de superfície, de volume e assim por diante. Graças a experiências variadas, umas mais engenhosas que as outras, Piaget provou que todas as crianças tinham de reconstruir as ideias, os conceitos ou, ainda, as teorias que parecem evidentes aos adultos.

Vamos dar um exemplo clássico das descobertas de Piaget. Com 4-5 anos, a criança julga que uma sequência de seis objetos espalhados contém mais objetos do que uma sequência de seis objetos amontoados um em cima do outro. Seis meses ou um ano mais tarde, ela descobre que é preciso desconfiar das percepções, e que uma sequência longa de objetos não é sinônimo de grande quantidade. Para se assegurar quanto à igualdade ou à diferença entre as duas sequências, ela irá recorrer à contagem ou à correspondência item a item. Do mesmo modo, Piaget mostrou que, no início de seu desenvolvimento, as crianças confundiam o peso e o volume, a ordem de chegada e a velocidade, e assim por diante. Colaboradores de Piaget também mostraram que as crianças precisavam explorar a linguagem para descobrir que ela era composta de palavras distintas. Ao escutar as frases na sequência, as crianças aprendem a refletir sobre a linguagem e segmentam a faixa sonora em unidades significativas. Quando começam a ler e a escrever, elas duvidam que se escreva tudo o que se fala. Numa primeira etapa, as crianças pensam que representamos o essencial da mensagem, como num desenho: os atores e a ação. Só depois de vários anos é que elas se convencem da existência dos artigos e das preposições. Em suma, graças à teoria de Piaget e de seus seguidores, hoje estamos convencidos de que tudo se aprende, ou melhor, tudo se constrói.

Dois autores americanos - Carrol (1963; 1974; 1975) e Bloom (1953; 1964; 1968; 1972a; 1972b; 1973; 1974a; 1974b) - também contribuíram para modificar completamente nossos conceitos pedagógicos. Eles provaram, sobretudo, que é errado pensar que certos indivíduos não "nasceram para 
estudar". O que mais diferencia os alunos é a velocidade da aprendizagem; alguns dominam a matéria em pouco tempo, enquanto outros são mais lentos. Isso não significa que esses últimos não serão capazes de assimilar os conceitos complexos e abstratos; eles simplesmente precisarão de mais tempo do que alguns de seus colegas. Quando conseguem atingir o mesmo critério de eficácia que os mais rápidos, os alunos lentos compreendem, tão bem como seus colegas, esses conceitos complexos e abstratos, sendo igualmente capazes de aplicar esses conceitos a problemas novos. Em suma, a qualidade da aprendizagem realizada não tem nenhuma relação com o tempo que se leva para alcançá-la.

Podemos afirmar, doravante, que todos os alunos são dotados para o estudo. Embora existam inúmeras provas disso, a mais impressionante demonstração foi dada por colaboradores de Bloom. Eles formaram três grupos de alunos escolhidos ao acaso. No início da experiência eles estão, portanto, diante de três grupos completamente equivalentes, selecionados sem nenhum tipo de critério que os diferenciasse de antemão; encontramos, no interior de cada um deles, uma pequena quantidade de alunos "fortes", muitos "médios" e alguns "fracos". A mesma matéria é ensinada aos três grupos; o que varia é o modo de ensinar. 0 primeiro grupo é ensinado da maneira habitual: os alunos são reunidos numa classe e assistem a aulas tradicionais. No segundo grupo, a matéria a ser assimilada é dividida em unidades de aprendizagem; embora cada uma delas seja ensinada coletivamente, no final de cada unidade os alunos são submetidos a um teste do tipo formativo; caso não tenham entendido bem a matéria, aproveitam para revê-la por meio das informações advindas da correção do teste. Chamamos esse procedimento de Pedagogia da Aprendizagem. No terceiro grupo, cada aluno conta com um preceptor, escolhido por sua competência e cuidadosamente formado, que explica as noções e os conceitos, tendo a possibilidade de ajustar diretamente a maneira de ensinar segundo o grau de compreensão de cada indivíduo. Os três grupos são submetidos ao mesmo teste final, cujo objetivo é avaliar o nível de aprendizagem que cada um deles alcançou. Constatamos que os alunos do primeiro grupo progrediram em proporções variáveis e, consequentemente, observamos uma distribuição gaussiana ${ }^{13}$ dos resultados. No segundo grupo, a distribuição dos resultados aproxima-se de uma curva em J: a maioria dos indivíduos apresenta um resultado próximo do máximo. O terceiro grupo, que se caracteriza pelo preceptorado, consegue, evidentemente, os melhores resultados: estes assumem claramente a forma de uma curva em J no ponto em que os mais fracos desse grupo alcançam resultados equivalentes aos dos

13 Nota da revisão técnica: curva normal. Para saber mais, ver: Morettin e Bussab (2006). 
mais fortes do primeiro grupo. Evidentemente, Bloom não pensa em estender o preceptorado a todos os alunos do mundo, o que seria completamente utópico. Na verdade, os resultados do grupo "preceptorado" permitem que ele torne visível a educabilidade dos alunos considerados os mais "limitados" e, portanto, que ele demonstre o poder do ensino. Um aluno "fraco" que disponha de condições ideais de aprendizagem pode se tornar tão competente quanto um aluno "forte" submetido a condições normais de ensino. Ao comparar com esse resultado ótimo, ele revela a eficácia da Pedagogia da Aprendizagem. Aplicada em classes normais, esse mecanismo permite que se alcancem resultados claramente superiores àqueles observados em classes comuns.

\section{EDUCAÇÃO DE MASSA E FORMAÇÃO DE ELITES, DOIS OBJETIVOS COMPATÍVEIS}

As ideias de Bloom são, frequentemente, qualificadas de utópicas. Para muitos - professores, pais e responsáveis políticos -, é irrealista desejar que todos os alunos sejam bem-sucedidos. Tocamos aqui num ponto crucial das representações comumente partilhadas pelo grande público. 0 fracasso de uma parte dos alunos teria algo de normal ou, ao menos, de inelutável. Ainda hoje, a ideia de que todos os indivíduos seriam educáveis num nível bastante alto continua sendo motivo de discussão. A esse respeito, é preciso lembrar as reações veementes com que a Lei Haby - que instaurou o curso secundário para todos - foi recebida na França. Em 1975, o ministro que dá nome à lei desejava abolir as especializações possíveis a partir do início do secundário e criar um tronco comum, constituindo assim uma educação básica com conhecimentos a serem igualmente distribuídos entre todos nessa fase da escolaridade. Alguns anos mais tarde, assistimos à publicação de uma série de livros cujos títulos são autoexplicativos. Citemos alguns deles: La génération sacrifiée [A geração sacrificada] (BENOIST, 1980), Voulez-vous vraiment des enfants idiots? [Vocês querem, de fato, filhos idiotas?] (MASCHINO, 1984), e L'enseignement en détresse [O ensino desesperado] (ROMILLY, 1984). Para todos esses autores, que transmitiam uma opinião amplamente compartilhada pela população francesa, a democratização do ensino secundário levava a um nivelamento por baixo. Dessa perspectiva, os fracassos escolares foram interpretados como sinais de falência da tentativa de fazer com que todos os alunos fossem bem-sucedidos. De maneira ainda mais clara, alguns afirmam que um sistema de ensino que ambicione ser bem-sucedido deve ser seletivo. Essa ideia é claramente defendida por Milner (1984) em seu livro sobriamente intitulado De l'école [Sobre a escola]. Ele explica que o próprio fato de eliminarmos o fracasso faz com que eliminemos o êxito. Abolir a repetência 
seria retirar a ameaça que, segundo ele, faz com que os alunos se esforcem. Mais ainda, generalizar o êxito para todos os alunos seria banalizá-lo, já que ele se tornaria o destino de todos.

Se essa acusação tivesse fundamento, os países que - como a Dinamarca, a Islândia, a Finlândia, a Noruega, o Reino Unido, a Suécia ou, ainda, o Japão - adotaram a aprovação automática ao longo dos nove primeiros anos de escolaridade deveriam caracterizar-se por um rendimento escolar bastante fraco, devido a um nivelamento por baixo. Vários estudos internacionais mostram que esses países geralmente se classificam entre os mais bemsucedidos, tanto com relação à leitura, à matemática ou às ciências. Falando cientificamente, está comprovado que a aprovação automática dos alunos pode se conjugar com um sistema de ensino de grande eficácia ${ }^{14}$.

É preciso enfrentar ainda outra objeção. Ela consiste no temor de que as ações que favorecem a democratização da escola se façam em detrimento dos melhores. Mais precisamente, isso equivale a temer que a média geral do rendimento escolar aumente devido ao avanço dos mais fracos, mas também à uniformização das competências em torno dessa média. Os anglo-saxões designam esse possível desvio por meio da expressão efeito Robin Hood. Em outras palavras, a igualdade de conhecimentos adquiridos seria alcançada freando o progresso dos melhores, e isso a fim de permitir que os mais lentos acompanhassem o ritmo. Os pedagogos se inspirariam, de alguma forma, no herói inglês que tirava dos ricos para dar aos pobres.

Essa objeção pede uma discussão ética que só podemos abordar superficialmente. Na verdade, podemos nos perguntar se é totalmente ilegítimo que os melhores ou os mais favorecidos contribuam para o desenvolvimento dos outros. Mas não nos aventuremos nessa reflexão sem antes examinar alguns dados empíricos, fornecidos pelos estudos internacionais conduzidos pela Associação Internacional para a Avaliação do Rendimento Escolar $(\mathrm{IEA})^{15}$. O IEA ${ }^{16}$ preocupou-se especialmente em examinar em que medida a democratização dos sistemas de ensino era incompatível com o surgimento das elites. Uma vez mais, a análise científica permite desmascarar uma ideia falsa que ainda é extremamente difundida.

Não é selecionando rigidamente os alunos a partir do fim do primário que teremos a garantia de formar elites numerosas e de alta qualidade. Pelo

14 Reunimos uma quantidade importante de provas em nosso livro Peut-on lutter contre l'échec scolaire? [É possível lutar contra o fracasso escolar?] (CRAHAY, 2007).

15 A ideia básica dessa associação é estudar o funcionamento dos diferentes sistemas de ensino a fim de confirmar ou invalidar ideias consagradas que giram em torno do funcionamento e alcance desses sistemas.

16 Nota da revisão técnica: para conhecer o IEA, veja o site http://www.iea.nl 
contrário, nos sistemas que orientam precocemente os alunos, é grande o risco de eliminar quem poderia fazer uma carreira escolar brilhante. Os erros de avaliação e de seleção são tão frequentes que acabam encurtando de maneira significativa o tempo de sobrevida no currículo de alguns alunos brilhantes. Na verdade, a orientação precoce e a seleção dos alunos só faz sentido na medida em que adiramos à teoria das aptidões anunciadas neste texto. A orientação precoce postula que as aptidões individuais são predeterminadas, imutáveis e identificáveis de maneira inequívoca por meio das ferramentas de seleção disponíveis. No caso contrário, o encaminhamento de um aluno para um curso técnico significa mais uma desistência quanto à possibilidade de fazer com que o aluno evolua do que uma verdadeira escolha.

Como já mencionamos, vale a pena refletir sobre o exemplo dos países nórdicos europeus (Dinamarca, Finlândia, Noruega e Suécia). Nesses países, os alunos têm de frequentar uma única estrutura de ensino durante nove anos, isto é, todos recebem o mesmo ensino durante todo esse tempo. É verdade que existem outros cursos optativos nessa fase, mas eles não apresentam a enorme variedade a que estamos habituados. Além do mais, durante esses nove anos de escola fundamental, todos os alunos estão a salvo do fracasso escolar, já que a repetência foi abolida. Os efeitos desse sistema, profundamente inspirado em valores democráticos, são apreciáveis. Um número significativo de alunos, nesses países, chegam ao ensino superior universitário ou não universitário e se saem bem. Além disso, o número de alunos que compõem o grupo dos que se saem muito bem é maior do que em nosso país, e isso em matemática, ciências ou leitura. Em suma, é preciso dar razão a Husen, o cientista sueco que inspirou a reforma do sistema de ensino de seu país, quando declara que a melhor maneira de produzir uma grande quantidade de alunos brilhantes consiste em retardar o momento da seleção. Dito de outra forma, o prolongamento da etapa da escolaridade que promove a formação e a convivência no espaço de formação faz com que aumente a quantidade de indivíduos brilhantes que ele pode produzir.

\section{A REPETÊNCIA É INEFICAZ}

Em nosso país, a ideia de uma escola em que os alunos jamais repetem causa espanto. Se as pesquisas a respeito do assunto forem confiáveis, a maioria dos professores continua acreditando na utilidade dessa prática pedagógica e, sobretudo, continua duvidando que seja possível administrar de outra maneira essa medida da heterogeneidade entre alunos. Tanto para eles como para um bom número de pais, a repetência é um mal necessário. Embora seja 
verdade que ela signifique a confirmação de um fracasso ou, pelo menos, a estigmatização social de uma dificuldade de aprendizado, continua sendo a melhor maneira de reagir a essa situação de fato. A repetência é considerada como uma forma de remédio pedagógico. Considerando que os ritmos de aprendizagem e de desenvolvimento variam de pessoa para pessoa, eles concluem que o programa, adequado para a maioria dos alunos, não o é para aqueles cujo amadurecimento psicológico é mais lento. Portanto, esses professores, a quem não falta coerência, avaliam que o fracasso escolar devese ao fato de que o ritmo de desenvolvimento de alguns alunos ajusta-se mal às exigências do programa. Faltando-lhes, de certa maneira, maturidade, esses alunos não conseguem acompanhar o avanço pedagógico que convém à maioria. A solução parece se impor nesse momento: é preciso restabelecer o equilíbrio entre as características desses alunos de desenvolvimento lento e as exigências que temos em relação a eles. Como? Fazendo-os repetir de ano, isto é, convidando-os a se integrar num grupo mais jovem. Desse modo, damos-lhes a possibilidade de tomar fôlego. Oferecemos-lhes um tempo de aprendizagem suplementar, respeitando, assim, seu ritmo de desenvolvimento. Portanto, a repetência é uma espécie de terapia por meio da qual damos aos alunos com dificuldade escolar a oportunidade de adquirir maturidade e de recomeçar com bases mais sólidas. Alguns ainda acrescentarão que a repetência permite aumentar a homogeneidade das classes, o que é benéfico para todos, já que o professor pode adaptar melhor o ensino às características do grupo de alunos.

\section{OS FATOS RECOLHIDOS CIENTIFICAMENTE NÃO CORROBORAM ESSA TEORIA}

Constatamos, primeiramente, que um grande número de alunos cuja entrada na escola primária foi retardada, bem como aqueles que repetiram de ano no início do ensino primário, repetem uma segunda ou uma terceira vez durante sua trajetória escolar. Também foi possível demonstrar que, com o mesmo nível de competência, os alunos que repetem ao longo do ensino primário ou no início do secundário abandonam com mais frequência a escola que seus colegas que, embora enfrentando dificuldades na escola, jamais repetiram. Em suma, sabe-se hoje que a repetência de um ano é sinal de outras repetências, aumentando o risco de abandono da escola.

Por outro lado, pouco mais de 200 pesquisas foram realizadas (sobretudo nos países anglo-saxões) a fim de determinar em que medida a repetência de um ano traria os benefícios esperados no nível da aprendizagem escolar dos alunos em dificuldade. Foram realizados dois tipos de pesquisa. No primeiro 
tipo, foi feito o acompanhamento de um grupo de alunos em dificuldade, e mediram-se os ganhos alcançados graças à repetência de um ano submetendo esses alunos a testes de conhecimento antes e depois de terem repetido de ano. Isso pode ser esquematizado da seguinte forma:

Ano perdido - Pré-teste - Ano repetido - Pós-teste

Esse tipo de pesquisa não tem grande valor, na medida em que não existe grupo de controle, isto é, não existe ponto de comparação. Portanto, não causa surpresa que, em todos os casos, se verifique um progresso entre 0 pré-teste e o pós-teste. Mas a que atribuir esses ganhos? À repetência? Ao amadurecimento espontâneo dos alunos? Ao ambiente familiar? Embora todas essas explicações sejam plausíveis, é impossível tomar uma decisão: nenhum cientista ousará afirmar que a evolução constatada deve-se fundamentalmente à repetência. Além do mais, quem pode afirmar que não teriam acontecido avanços equivalentes ou superiores se esses alunos tivessem sido aprovados? Os professores que acompanham os alunos repetentes na classe encontramse na mesma posição dos pesquisadores que realizaram esse tipo de estudo: eles constatam, provavelmente, que os alunos progridem com relação ao ano anterior, mas não estão em condições de afirmar que não teria sido melhor se os alunos tivessem sido aprovados.

No segundo tipo de pesquisa, comparamos o desenvolvimento de dois grupos de alunos com dificuldade escolar. Os pesquisadores constituem duas amostragens paralelas de alunos, isto é, no presente caso, de nível escolar idêntico e bem fraco, mas dos quais, no entanto, os primeiros foram promovidos para o ano seguinte, enquanto os outros tiveram de repetir de ano. Os dois grupos são testados diversas vezes: primeiramente, no final do primeiro ano da pesquisa, durante a qual foram identificados os alunos com dificuldade; em seguida, um ano mais tarde, e, em determinadas pesquisas, durante vários anos sucessivos. Esse esquema de pesquisa pode ser representado assim:

Grupo de alunos repetentes: Ano N - Teste 1 - Ano 2 - Teste 2 - Ano N+1 Teste 3

Grupo de alunos aprovados: Ano N - Teste 1 - Ano 2 - Teste 2 - Ano N+1 Teste 3

O que as pesquisas que respeitaram esse plano de investigação apontam? 
De um modo geral, observamos que, a despeito do nível inicial igualmente fraco, os alunos aprovados realizam progressos muito superiores aos dos alunos repetentes. Mais precisamente, o mecanismo de pesquisa utilizado nessa categoria de estudo permite que se façam três observações. Para sustentá-las, utilizemos o esquema apresentado a seguir:

1. Se comparamos os resultados do teste 1 dos dois grupos de alunos, não observamos uma diferença significativa.

2. Se comparamos os resultados dos testes 2 e 3 dos dois grupos de alunos (comparação com a idade constante ${ }^{17}$ ), observamos uma diferença significativa em favor dos alunos aprovados.

3. A comparação dos resultados dos alunos repetentes no teste 3 com os resultados dos alunos aprovados no teste 2 (comparação com nível escolar constante ${ }^{18}$ ) não revela uma diferença significativa.

A primeira observação confirma que, no início, os dois grupos são equivalentes do ponto de vista das competências medidas pelo teste. A segunda indica que, com a idade constante, os alunos que foram aprovados, embora tenham enfrentado dificuldades escolares, atingiram um nível de competência superior à de seus colegas que repetiram de ano. Assim, se compararmos dois alunos fracos de 8 anos, dos quais um repetiu o primeiro ano e o outro passou para o segundo, esse último demonstrará competências superiores às do aluno que ficou no primeiro ano. A terceira observação mostra que, com nível escolar constante, os alunos repetentes atingem o mesmo nível de competência que seus colegas que foram aprovados, apesar de suas dificuldades escolares. Nesse caso, se compararmos dois alunos no final do segundo ano, dos quais um repetiu o primeiro ano e o outro não, seus desempenhos são equivalentes. No entanto, é preciso ressaltar que, para atingir esse nível de competência, o aluno repetente teve um ano a mais, que representa, realmente, um ano perdido.

Esses resultados de pesquisa não permitem afirmar que a repetência seja uma espécie de remédio pedagógico e que ela permita que os alunos com dificuldade tomem pé a fim de aproveitar melhor a sequência dos aprendizados. Essa conclusão é ainda mais sólida uma vez que a quantidade de pesquisas que chega a esses resultados é significativa ${ }^{19}$.

17 Embora os alunos dos dois grupos tenham a mesma idade, alguns têm um ano de estudo a mais que os outros.

18 Comparamos os alunos quando todos terminaram um nível escolar preciso, pouco importando que alguns (os repetentes) sejam mais velhos.

19 Um amplo levantamento desses estudos encontra-se em nosso livro Peut-on lutter contre l'échec scolaire? [É possível lutar contra o fracasso escolar?] (CRAHAY, 2007). 
Por que existe uma oposição tão clara entre os resultados das pesquisas e as crenças de inúmeros professores? Antes de tudo, importa ressaltar que todos os professores da comunidade francesa não estão convencidos das vantagens da repetência, sendo que uns 20\% demonstram mais do que reservas com relação a essa prática pedagógica tradicional. Nos países do norte da Europa, os professores não compreendem que ainda possamos recorrer a essa medida, que, sob certos aspectos, lhes parece bárbara.

Na verdade, um grande número de professores é vítima de uma ilusão. Quando repetem um aluno de ano, eles constatam que, ao longo do ano, o aluno repetente progride. Essa evolução é normal; ela é resultado, especialmente, do amadurecimento. O que o professor não sabe é que essa criança provavelmente teria progredido mais se tivesse sido aprovada. Só os quadros de pesquisa que organizam a comparação dos dois grupos equivalentes permitem que se faça essa observação.

Esses mesmos professores ainda confundem a repetência com a repetição de uma aprendizagem que não deu certo. Repetir de ano significa outra coisa. Significa separar o aluno de seu grupo de colegas e colocá-lo em posição de inferioridade com relação a eles. Significa também obrigá-lo a recomeçar a trabalhar indistintamente competências adquiridas e não adquiridas. Ninguém contesta a utilidade de retomar uma aprendizagem mal realizada, mas será que é necessário recomeçar do zero quando uma parte do caminho já foi percorrida? Além do mais, em matéria de solução para as dificuldades de aprendizagem, sabemos que sua eficácia será tanto maior quanto a correção trazida pelo professor vise precisamente ao ponto de obstrução e ocorra logo após o momento em que a criança depara com o obstáculo. Em última análise, a repetência constitui uma forma grosseira de reagir às dificuldades de alguns alunos. É o mesmo que ligar a serra elétrica quando seria preciso usar o bisturi.

Vamos tentar explicar por que a repetência prejudica os alunos com dificuldade escolar. Uma primeira pergunta deve ser feita: o que os alunos sentem quando repetem de ano? As entrevistas feitas com alguns deles revelam o sofrimento experimentado. Alguns falam de vergonha, e todos de tristeza e mal-estar; eles temem o sarcasmo dos colegas, a cólera dos pais, o afastamento dos amigos... Às vezes, é da postura dos professores que eles têm medo. Por outro lado, a maioria dos alunos repetentes não sabe muito bem por que eles têm de repetir de ano. Na verdade, é raro que o professor tenha reservado tempo para se encontrar individualmente com cada um deles, a fim de thes explicar os motivos que justificavam aquela decisão. 
Esses temores não deixam de ter fundamento. A entrevista com os alunos que nunca repetiram de ano é instrutiva. Para eles, o aluno repetente é um mau aluno: ele não vale nada, não é muito inteligente, é preguiçoso... No dizer de alguns desses alunos bem-sucedidos, o repetente pode se tornar 0 bode expiatório dos colegas e também do professor. Para outros, a solicitude que alguns professores demonstram com relação aos repetentes revela publicamente a fraqueza deles.

Quando colocamos lado a lado, as declarações dos alunos repetentes e as dos bem-sucedidos, descobrimos que os alunos com dificuldade escolar recebem um rótulo ridículo difícil de usar. Eles não precisam mais simplesmente superar seus problemas de aprendizagem; eles precisam, além disso, enfrentar um ambiente social que, embora nem sempre hostil, é inibidor. Dentro da cabeça, também, os pensamentos adquirem tons sombrios. Deve-se temer que grande parte dos repetentes raciocine da seguinte maneira: se eu repeti é porque não sou capaz de estudar. E se eu não sou inteligente, de que adianta tentar aprender, já que, de todo modo, não vou conseguir?

Essa atitude de resignação provocada pela repetência já é bem conhecida e estudada hoje pelos psicólogos. A esse respeito, eles falam de uma sensação de incompetência adquirida, querendo dizer com isso que é a convicção de ser incompetente que torna os indivíduos incapazes de acompanhar determinadas aprendizagens ou de alcançar determinados desempenhos.

Diante disso, podemos levantar a hipótese de que a repetência de um ano freia o aprendizado escolar dos alunos em dificuldade de duas maneiras. Por um lado, é grande o risco de que o aluno repetente fique com uma sensação de incompetência adquirida e encare qualquer aprendizagem nova como se já estivesse derrotado de antemão. Por outro, é grande o risco de que o aluno repetente se veja diante de um ambiente social em que se misturam o sarcasmo e a solicitude mal interpretada.

\section{DIFERENCIAR... SIM, MAS COMO?}

A espécie humana é rica em diversidade. Toda sala de aula é um microcosmo no qual essa heterogeneidade básica se reflete. 0 professor não pode agir como se estivesse diante de uma série de alunos padronizados que reagiriam, todos, da mesma maneira. Diante de duas ou três dezenas de alunos, ele sabe que o desenvolvimento físico, os ritmos de aprendizagem, os estilos cognitivos, os níveis de linguagem, os interesses e as motivações variam. Diante disso, uma pergunta se impõe: podemos exercer a mesma ação educativa com relação a todos esses alunos? 
É comum afirmar que é preciso diferenciar o ensino levando em conta as características dos alunos. Legrand (1995) teve o mérito de ressaltar que o termo “diferenciação" pode assumir dois significados opostos. Por um lado, podemos adaptar o ensino de modo que ele conduza o aluno para um objetivo social e/ou profissional. Por outro lado, podemos atribuir um objetivo comum a todos os alunos e nos esforçarmos para adaptar os recursos de ensino à sua diversidade. A primeira definição leva à escola sob medida, que é coerente com a noção de igualdade de oportunidades. Consideramos que as diferenças individuais têm origem em características estáveis e imutáveis. Como consequência, adaptamos os objetivos e a formação às especificidades dos alunos. A segunda definição concorda com o princípio de igualdade de conhecimentos adquiridos. Alimentada pelo ideal de justiça corretiva, a diferenciação consistirá em oferecer mais e/ou de outra maneira àqueles que enfrentam mais dificuldade. Portanto, a forma de diferenciação adotada depende, antes de tudo, da escolha ética que se faz. Nós optamos decididamente pela igualdade de conhecimentos adquiridos, ou seja, todos os alunos têm direito a conhecimentos considerados fundamentais.

São inúmeros os professores que compartilham da convicção de que quanto mais individualizado for o ensino, maior sua qualidade. Eles esforçam-se em organizar um ambiente no qual cada aluno possa progredir no seu ritmo, em atividades de aprendizagem autosselecionadas e autodirigidas. Eles reúnem ou produzem um material de aprendizagem que seja utilizável individualmente e adaptável ao estilo de cada um. Assim, os alunos são levados a trabalhar sozinhos, com a ajuda de fichas, manuais ou, mais raramente, programas de computador.

Essa organização pedagógica foi popularizada pelo movimento da escola nova. No entanto, essa forma de ensino também tem seus opositores. Eles observam que, nessas condições, cada aluno se encontra só diante do material didático, avançando em seu próprio ritmo; os mais rápidos avançam cada vez mais rápido e os mais lentos cada vez mais lentamente. Podemos resumir assim o argumento principal: quanto mais o ritmo e as condições de aprendizagem são determinados pelos próprios alunos, mais as diferenças existentes entre eles aumentam.

Foram realizados numerosos estudos sobre esse tema nos Estados Unidos. O mapeamento desses estudos não permite que se chegue a uma conclusão quanto à eficácia dos mecanismos de individualização. Pelo contrário, parece que começa a se esboçar uma tendência oposta. No entanto, é delicado 
concluir de maneira peremptória quanto aos vários limites metodológicos dos estudos existentes. Por outro lado, parece que existe uma relação negativa entre o fato de o professor criar as condições para que cada um determine, à sua maneira, seu ritmo de avanço e o tempo que os alunos dedicam ao aprendizado. Contudo, esse efeito negativo pode ser compensado pela postura do professor: o investimento dos alunos na aprendizagem cresce quando o professor se mostra atento a seus avanços e pronto a reagir assim que um deles se distrai.

Diante disso, devemos abandonar qualquer projeto de individualização? Sem dúvida, não. Não obstante, seria conveniente que fizéssemos disso mais um objetivo do que uma panaceia. Essa organização pedagógica pressupõe que o aluno seja capaz de se impor uma rigorosa disciplina de trabalho. Sozinho diante do material escrito, ele deve encontrar dentro de si a vontade de avançar e de superar suas dificuldades. Em suma, aprender sozinho pressupõe, ao mesmo tempo, uma motivação intrínseca e a capacidade de autogerir a compreensão dos documentos escritos e de lidar com a informação para armazená-la na memória de forma duradoura. Ora, o ser humano é, antes de tudo, um animal social. A criança pequena procura a companhia dos colegas; ela realizou seus primeiros aprendizados na relação com a mãe e com o pai. Ao entrar na escola maternal, ela precisou se adaptar ao aprendizado em grupo. A posição individual é ainda mais exigente: é preciso conduzir o aluno pouco a pouco até ela.

Só podemos esperar vantagens imediatas limitadas da organização dos mecanismos de aprendizagem individualizados. Em compensação, podemos esperar mais da organização por grupos segundo necessidades. Essa modalidade de agrupamento de alunos foi muito testada nos países anglosaxões dentro do quadro de referência do projeto Joplin. Segundo esse projeto, os alunos são reunidos numa classe heterogênea de acordo com a idade. No entanto, eles saem da classe para participar de determinadas aprendizagens - leitura ou matemática - que se desenvolvem em grupos homogêneos. Nesse tipo de escola:

- O tempo passado no grupo homogêneo é claramente inferior ao tempo passado na classe heterogênea, resultando no fato de que o grupo com o qual as crianças mais se identificam é esse último.

- A constituição de grupos homogêneos apoia-se na avaliação de uma competência específica e não mais na de uma aptidão geral. 
- Os grupos são flexíveis, sendo reorganizados regularmente segundo o progresso dos alunos.

O balanço dos estudos realizados para avaliar a eficácia do projeto Joplin é claramente positivo. Podemos afirmar, portanto, que a organização flexível de grupos homogêneos constituídos com base no nível de domínio de uma competência específica produz efeitos positivos inegáveis. Segundo nosso ponto de vista, as vantagens determinantes são: essa maneira de administrar a heterogeneidade dos alunos é vantajosa para todos eles e, em especial, para os alunos fracos.

A ideia embrionária que estava presente no projeto Joplin foi ampliada por Goodlad e Anderson, cuja obra de 1959, The non-graded elementary school [A escola fundamental sem níveis], suscitou a criação de um grande número de escolas sem classes por idade. Trata-se de romper radicalmente com a divisão tradicional do currículo escolar em anos. Segundo os autores, essa organização escolar, herdada dos jesuítas, não tem nenhuma base psicológica. Eles sugerem que se busque uma organização escolar que leve em conta três ideias-chave:

1. As diferenças na velocidade de aprendizagem entre os indivíduos não são características imutáveis. Elas dependem de diversos fatores (clareza das explicações dadas pelo professor, confiança do aluno em si, ambiente familiar, etc.). Portanto, não se pode pensar em adotar esse critério para que ele funcione segundo uma classificação estável dos indivíduos.

2. Os ritmos de avanço variam segundo a área de competências: alguns alunos avançam rapidamente em matemática, enquanto outros se mostram mais à vontade no aprendizado da leitura.

3. A velocidade de avanço numa área de competências não é linear: alguns podem não sentir nenhuma dificuldade nas primeiras etapas de uma aprendizagem, e depois penar nas etapas posteriores. Outros começam com dificuldade e em seguida avançam facilmente.

Consequentemente, Goodlad e Anderson (1959) propõem que se recorra a um agrupamento flexível de alunos. Evidentemente, o objetivo é permitir que eles avancem nos aprendizados num ritmo que lhes convenha, sem, apesar disso, cair no espontaneísmo ou no relaxamento. A velocidade de avanço não é determinada pelos próprios alunos. Em última instância, é o professor que administra esse aspecto decisivo da situação didática. 
A eficácia dessa forma de organização da escola foi demonstrada por uma série de estudos rigorosos. Contudo, existe uma condição fundamental para o sucesso: a organização do ensino segundo uma estrutura que Goodlad e Anderson (1959) chamam de Continuous progress [Progresso continuado], na qual as competências a serem aprendidas são organizadas de acordo com uma hierarquia de níveis que cobre a totalidade do programa a ser percorrido. A escola primária é dividida em dois ciclos de três anos (ciclo 1-3 e ciclo 4-6). No fim do primeiro ciclo (e do segundo), é preciso que se tenha alcançado um certo nível de competência em leitura e em matemática. Por outro lado, os grupos são recompostos regularmente, aproximadamente a cada três meses. Assim, na leitura, o programa a ser assimilado durante 0 primeiro ciclo é dividido em 12 níveis ou etapas hierarquizadas, cada uma delas correspondendo a um período de aprendizagem. Assim que se pode demonstrar que uma criança domina as competências próprias do primeiro módulo, ela muda de grupo, passando para o grupo em que o professor está empenhado em promover o domínio do nível 2, e assim por diante. Nesse sistema, uma criança que atinge o nível 12 em leitura no final do segundo ano passa simplesmente para o segundo ciclo (nesse caso, para o ciclo 4-6). 0 aluno mais lento que, ao final de três anos, se encontra no nível 10, iniciará o quarto ano num grupo em que o esforço seja adquirir o domínio do nível 11. Após três meses, ele passará para um nível superior.

Essa estruturação modular geralmente é reservada para as matérias principais. Para os outros aprendizados, recorre-se a outras modalidades de agrupamento: grupos de interesse, grupos etários, etc.

É preciso insistir nisto: a eficácia dessa forma de organização escolar depende muito da natureza estruturada do programa e do cuidado em recompor os grupos a cada dois ou três meses, com base numa avaliação minuciosa das competências dominadas. Constituímos classes de alunos homogêneas quanto a seus pré-requisitos ou a seus conhecimentos anteriores. Retomamos, assim, uma recomendação feita por Bloom em Caractéristique individuelles et apprentisages scolaires [Características individuais e aprendizagens escolares] (1979). Nessa obra, o pedagogo americano demonstrou que a diversidade de competências e de conhecimentos de partida determina, em grande parte, a variabilidade dos resultados do ensino. Ao mesmo tempo, ele provou a eficácia das revisões periódicas dos níveis dos alunos. Desse modo, todos encaram o ensino dominando os pré-requisitos considerados necessários. Fica evidente, assim, a vantagem de um mecanismo pedagógico no qual os grupos são recompostos em intervalos curtos tendo como referência as aquisições: 
o professor pode apostar numa base comum de conhecimentos dominados e direcionar sua ação para uma amostragem precisa de competências a construir.

Para compor os grupos homogêneos é preciso fazer avaliações no final de cada período. Os testes ou provas aos quais os alunos são submetidos assumem uma função de investimento: a finalidade é diagnosticar o mais precisamente possível onde cada aluno se situa na sequência de aprendizagens. Em outras palavras, para chegar a agrupamentos pertinentes de alunos os professores fazem avaliações regulares, direcionadas para as competências em desenvolvimento. Desse modo, a função da avaliação é modificada: não se trata de classificar os alunos uns em relação aos outros, mas de situar precisamente cada um numa hierarquia de saberes. Essa iniciativa parece extrair sua eficácia, em última análise, de três características:

1. uma forte estruturação do programa dentro do qual as aprendizagens a serem executadas são organizadas em módulos hierarquizados, o que pressupõe, ao mesmo tempo, um reagrupamento das competências em conjuntos de saberes e de savoir-faire a serem desenvolvidos com sinergia e uma articulação hierárquica desses conjuntos;

2. um dispositivo regular de avaliações direcionado para as competências a serem desenvolvidas, avaliações estas que desembocam no controle das aprendizagens por meio de uma recomposição dos grupos de alunos;

3. um ensino coletivo que, graças à homogeneização dos grupos de alunos segundo suas competências no campo a ser desenvolvido, pode se apoiar numa base de pré-requisitos comuns e visar a alvos precisos de aprendizagem.

Existem ainda duas outras formas eficazes de diferenciação: o tutorado e a aprendizagem cooperativa.

O tutorado consiste em pedir que os alunos que dominam uma competência auxiliem seus camaradas que enfrentam dificuldade. A experiência mostra que todos podem se beneficiar desse tipo de situação.

$\mathrm{Na}$ aprendizagem cooperativa, compomos grupos heterogêneos, isto é, que reúnem alunos fortes e alunos fracos. Estes últimos são estimulados a colaborar no estudo de uma matéria ou na aquisição de uma competência. No final da sessão de trabalho, os alunos do grupo se submetem a um teste; o professor calcula a média das notas e chama a atenção dos membros do grupo para o desempenho de todos. O objetivo, na verdade, é suscitar um sentimento de 
responsabilidade coletiva. Para além do procedimento didático, a dimensão ética é evidente: renunciamos a uma escola marcada pelo individualismo e pela meritocracia, em que cada aluno é considerado responsável somente por seus avanços, em favor de uma escola na qual todos se sentem solidários com o progresso dos outros.

\section{COMO PÔR A AVALIAÇÃO A SERVIÇO DO APRENDIZADO DOS ALUNOS?}

Não se pode conceber um sistema de ensino sem avaliação. No entanto, é preciso perguntar: por que avaliar? Quando e como fazê-lo?

A avaliação conduz, geralmente, a uma decisão e, consequentemente, a um controle. Podemos, por exemplo, avaliar no início do ciclo de formação, a fim de selecionar os alunos que poderão ter acesso a ele ou não. É o que acontece nos casos dos exames de acesso, em que a decisão a ser tomada está relacionada à admissão ou à recusa do aluno; o controle consiste numa triagem ou numa seleção. No ensino primário e no ensino secundário, a avaliação é feita, sobretudo, no final do período de formação. 0 objetivo, então, é decidir se tal indivíduo domina ou não uma determinada competência e, no final do ciclo, certificar um conjunto estruturado de competências, ou mesmo uma especialização. Nesse caso, falamos de avaliação somativa. A isso se segue o controle, já que o indivíduo certificado pode considerar que sua formação no campo avaliado está terminada ou não. Falaremos de avaliação formativa quando o teste ou prova for concebido de modo a diagnosticar em que etapa do processo de aprendizagem o aluno enfrenta dificuldades. Nessa perspectiva, procurar-se-á saber qual componente da competência visada apresenta problema, a fim de decidir a melhor maneira de reajustar o processo de ensino.

A natureza dos exames muda segundo a função que a avaliação assume. Quando se trata de decidir quais alunos serão admitidos para seguir uma etapa da formação, podemos nos ater ao teste dos pré-requisitos dessa formação. Ainda mais óbvio é o caso em que uma instituição decide limitar o acesso dos estudantes e aplicar um numerus clausus por meio da organização de um concurso: é feita uma prova suficientemente difícil para que se possam identificar os indivíduos que apresentam, no mais alto nível, as características que predizem melhor o futuro êxito. No caso de uma avaliação somativa, convém determinar em que medida os alunos dominam as competências fundamentais designadas como o objetivo de um mecanismo de formação. Consequentemente, vamos nos preocupar em vasculhar o leque de objetivos 
perseguidos. As questões que dizem respeito a um campo particular visam, sobretudo, a abranger a competência global ou integrada que o processo gradual de ensino preocupou-se em construir. Vamos nos esforçar para evitar um erro que, infelizmente, é por demais frequente: fazer com que a avaliação se concentre no conhecimento de detalhes ou de competências secundárias, muito específicas, inferindo daí o domínio das competências num nível global. Quando a intenção é formativa, temos ainda um outro ponto de vista. Nesse caso, é legítimo privilegiar as questões que se referem a aspectos bem particulares da aprendizagem, já que se trata de diagnosticar da maneira mais precisa a origem daquilo que impede a aprendizagem.

Quando observamos as práticas de avaliação dos professores, saltam aos olhos as inúmeras confusões de perspectiva que pesam sobre o bom funcionamento das instituições educacionais. Alguns mestres encaram a avaliação de final de ano como se se tratasse de um exame prognóstico; outros confundem avaliação formativa e somativa. Nessa área, dois fatores parecem combinar seus efeitos negativos: a tradição meritocrática da escola e a influência da psicometria na avaliação escolar.

A escola tem a tradição de construir hierarquias de excelência. Nada mais lógico, portanto, que ela tenha privilegiado uma forma de avaliação que produz uma classificação dos indivíduos adaptada à distribuição gaussiana. A propósito disso, falamos de avaliação normativa na medida em que a curva de Gauss considerada normal torna-se a norma. As consequências desse desvio nas práticas de avaliação dos professores são evidentes: sentindose obrigados a produzir uma hierarquia ou uma classificação dos alunos, os mestres privilegiam as questões que apresentam maiores possibilidades de detectar as diferenças entre os alunos da classe. Eles também se esforçam em criar uma escala - geralmente artificial - para cada exame, a qual, idealmente, desembocará numa distribuição gaussiana das notas. Pode-se, então, situar o desempenho de cada indivíduo nessa escala, o que equivale a avaliar cada aluno por meio da referência aos colegas. Em consequência disso, os melhores do grupo são considerados como os bons alunos, sem que se faça uma referência explícita a um critério externo. De modo complementar, o mau aluno é aquele que sabe menos que os colegas. Isso não significa que ele não tenha atingido os objetivos designados a seu nível de estudo; pode ser que ele simplesmente se encontre num grupo de alunos especialmente avançados. Utilizando tal avaliação, o professor sempre descobrirá maus alunos na classe (deveríamos escrever menos bons). Isso lhe permitirá decretar, eventualmente, a existência de um ou dois fracassos. 
Por outro lado, nosso sistema de ensino exige que os professores se manifestem a cada final de ano quanto à possibilidade de cada aluno ser admitido na série seguinte. Essa responsabilidade, inscrita na legislação escolar, estimula os professores a pôr em prática uma avaliação prognóstica, isto é, a antecipar em que medida cada aluno está apto a acompanhar os ensinamentos da série seguinte. Ora, a avaliação prognóstica é, por essência, seletiva: interrogar-se sobre os alunos aptos a acompanhar com sucesso um grau de ensino posterior significa, necessariamente, supor que alguns não são capazes de fazê-lo e procurar identificá-los. Consequentemente, a maioria dos professores prepara seu exame de avaliação de final de ano de modo a classificar os alunos (avaliação normativa) e a identificar aqueles aptos a acompanhar com sucesso o ensino da série posterior (avaliação prognóstica). Desse modo, os professores são levados, fatalmente, a privilegiar as questões discriminativas.

Aqueles que sonham com uma escola que busque a igualdade de conhecimentos adquiridos se posicionarão no contrapé dessa concepção meritocrática e seletiva de escola. Para eles, a missão do ensino não é fabricar hierarquias de excelência, e sim estimular o máximo de aprendizagens num número máximo de alunos. A avaliação de final de período de ensino deve ser somativa, isto é, deve possibilitar que se estabeleça em que medida cada aluno domina as competências que foram objeto do ensino e em que pontos ainda se pode avançar ${ }^{20}$.

Igualmente importante: para conduzir a maioria - idealmente, a totalidade dos alunos a um mesmo nível de sucesso, apesar de suas diferenças iniciais, é preciso fazer, necessariamente, adaptações frequentes no processo de ensino. Convém, desde logo, praticar a avaliação formativa com a maior frequência possível. Como foi indicado acima, esta se diferencia basicamente da avaliação somativa por sua natureza diagnóstica: seu principal objetivo é identificar os obstáculos que o aprendiz não conseguiu superar. Ela deve desembocar num duplo controle: um, situado no nível da aprendizagem do aluno; o outro, no nível da atuação pedagógica do professor. Informado especificamente daquilo que ele não domina, o aluno é obrigado a se aperfeiçoar naquele ponto preciso. Quanto ao professor, conhecendo as deficiências específicas de cada aluno, presume-se que ele as leve em conta

em sua maneira de diferenciar o ensino.

20 Estes também sonharão com uma modificação da legislação escolar: a pergunta "o aluno está apto a acompanhar os ensinamentos da série seguinte?" seria substituída por esta pergunta dupla: "Que saberes e savoir-faire esse aluno dominou? Que outros saberes o professor da série seguinte deverá rever com ele?". 


\section{How can school be fairer and more effective?}

Abstract: Relying on a wide survey of researches and studies by major thinkers from the education domain, Marcel Crahay writes here about the relationship between ethical choices and educational mechanisms and practices which frame the teaching and apprenticeship process. The author deals with the kinds of mechanisms and practices which have achieved best results from the point of view of a fairer knowledge allocation. He analyzes the relationship between these practices an ethical principles of justice as well. He concludes that acquired knowledge equity, which is based on corrective justice principle, is the most appropriate pedagogical ideology for basic school because it considers various requisites researches have suggested to be necessary for apprenticeship for all, such as respecting distinct apprenticeship paces and the need for continued adjustment and changes in the teaching process, based on formative evaluation. Moreover, this pedagogical ideology takes into account scientific evidence of the non-existence of natural gifts, opposing to educational mechanisms and practices that provide unequal teaching opportunities because of the meritocracy principle.

Key words: Educational practices. Inequality at school. Equity. Teaching. Basic education. 


\section{REFERÊNCIAS}

ALAIN. Propos sur l'éducation. Paris: Reider, 1935.

BECKER, G. S. Human capital: A theoretical and empirical analysis, with special reference to education. 3. ed. Chicago: University of Chicago Press, 1993.

BENOIST, J. La generation sacrifiee. Paris: Denoël, 1980.

BLOOM, B.S. Thought processes in lectures and discussions. Journal of General Education, n. 7 , p. 160-169, 1953.

- Stability and change in human characteristics. New York: Wiley, 1964.

. Learning for mastery. Evaluation Comment, v. 1, n. 2, p. 34-42, 1968.

. L'innocence en pédagogie. Éducation. Tribune Libre, v. 80, n. 3, p. 3-18, 1972a.

Apprendre pour maîtriser. Paris: Payot, 1972b.

. Recent developments in mastery learning. Educational Psychologist, n. 10, p. 204-221, 1973.

. Time and learning. American Psychologist, n. 29, p. 682-686, $1974 a$.

. An introduction to mastery learning. In: BLOCK, J. H. (Ed.). Schools society, and mastery learning. New York, Holt: Rinehart and Winston, 1974b.

. Human characteristics and school learning. New York: McGraw-Hill, 1976.

. Caractéristiques individuelles er apprentissage scolaire. Bruxelles: Labor; Paris: Nathan. Tradução em francês par. V de Landsheere, 1979. Le défi des deux sigmas. In: CRAHAY, M.; LAFONTAINE, D. (Eds). L’art et la science de l'enseignement. Bruxelles: Labor, 1986, p. 97-128.

BOURDIEU, P. L'école conservatrice. L'inegalité sociale devant l'école et devant la culture. Revue Française de Sociologie, n. 3, p. 325-347, 1966.

MORETTIN, P. A.; BUSSAB, W. O. Estatística básica. São Paulo: Atual, 2006.

CARROLL, J. B. A model of school learning. Teachers College Record, n. 64, p. 
723-733, 1963.

. Fitting a model of school learning to aptitude and achievement data over grade levels. In : GREEN, D. R. (Ed.). The aptitude-achievement distinction: measurement. Carmel, California: CTB/McGraw-Hill, 1974.

The teaching of french as a foreign language in eight countries. New York: Willey, 1975.

CHAPPELLE, G.; CRAHAY, M. (Org.). Réussir à apprendre. Paris: Presses Universitaires de France, 2009.

CHATEAU, J. La culture générale. Paris: Vrin, 1968.

CLARAPÈDE, E. L’École sur mesure. Lausanne: Payot, 1920.

CRAHAY, M. Tetê bien faite, tête bien pleine? Recadrage constructiviste d'un vieux dilemma. Perspectives, v. XXVI, n. 1, p. 59-89, mar. 1996.

. Um bilan des recherches processus-produit. L'enseignement peut-il contribuer à l'apprentissage des eleves et, si oui, commentt. Genebra: Carnet dês sciences de l'éducation, 2006.

. Peut-on lutter contre l'échec scolaire?. 3. ed. Bruxelas: De Boeck, 2007.

Psychologie de l'éducation. (Quadrige). 2. ed. Paris: Presses Universitaires de France, 2010.

; DUTRÉVIS, M. (Org.). Psychologie des apprentissages scolaires. Bruxelas: De Boeck, 2010. (Coleção Ouvertures Psychologiques).

(Org.). L'école peut-elle être juste et efficace? 2. ed. revista com colaboradores e aumentada. Bruxelas: De Boeck, 2013.

. VERSCHAFFEL, L.; DE CORTE, E.; GRÉGOIRE, J. (Org.). Enseignement et apprentissage des mathématiques: que disent lês recherches psychopédagogique? Bruxelas: De Boeck Université, 2005.

DEROUET, J. L. Ecole et justice: de l'égalité des chances aux compromis locaux. Paris: Métaillé, 1992.

DUBET, F.; MARTUCELLI, D. A l'école: sociologie de l'expérience scolaire. Paris: Seuil, 1996. 
DURKHEIM, E. L'évolution pédagogique em France. 2. ed. Paris: Presses Universitaires de France, 1985.

GOODLAD, J. I.; ANDERSON, R. H. The nongraded elementary school. New York: Harcourt, Brace and World Inc., 1959.

HAMELINE, D. Courants et contre-courants dans la pédagogie contemporaine. Sion: Office de Documentation er d'Information Scolaire, 1986.

LEGRAND, L. Les différenciation de la pédagogie. Paris: Presses Universitaires de France, 1995.

MASCHINO, M. Voulez-vous vraiment des enfants idiots? Paris: Hachette, 1984.

MILNER, J.C. De l'ecole. Paris: Seuil, 1984.

MOTTIER-LOPÈS, L.; CRAHAY, M (Org.) Évaluation en tension. Entre la regulation des apprentissages et le pilotage des systems. Bruxelas: De Boeck, 2009. (Coleção Pédagogie en développement).

PAQUAY, L.; CRAHAY, M.; DE KETELE, J. M. (Org.) L'ánalyse qualitative dans les recherches en éducation: Des pratiques de recherche aux critères de qualité. Bruxelas, De Boeck \& Larcier: 2006.

PIAGET, J. Introduction à l'épitemologie génétique. Paris: Presses Universitaires de France, 1970.

ROMILLY, J. L’enseignement en détress. Paris: Julliard, 1984.

TOURAINE, A. Critique de la modernité. Paris: Les Éditions Fayard, 1992. 510 p.

RECEBIDO: Agosto de 2013.

APROVADO: Setembro de 2013. 